\title{
NO SOBE E DESCE DAS GANGORRAS: SENTIDOS QUE ROMPEM FRONTEIRAS ${ }^{1}$
}

\author{
SABRINA SANT'ANNA RIZENTAL ${ }^{2}$ \\ IEL - Instituto de Estudos da Linguagem \\ Universidade Estadual de Campinas \\ Rua Sérgio Buarque de Holanda, nº 571 - 13083-859 - Campinas - SP - Brasil \\ sabrina.santanna.k@gmail.com
}

\begin{abstract}
Resumo: Uma notícia traz enunciados e imagens que se imbricam na contradição constitutiva de sujeitos e sentidos. A notícia de um evento lúdico realizado na fronteira que separa o México dos EUA possibilita entradas de leitura para pensar os processos migratórios, na relação entre as fronteiras simbólicas constituídas na e pela linguagem. Este artigo traz análises de recortes desta notícia, focalizando diferentes modos de formulação que movimentam sentidos numa atualização da memória a partir de determinadas posições discursivas. Da mesma forma que as gangorras sobem e descem, nesse movimento simbólico de continuidade e ruptura, os dizeres sobre os migrantes e os refugiados ressoam afetados por uma construção imaginária sobre aqueles que ocupam esses lugares. Palavras-chave: fronteira; migrantes; refugiados; discursos.
\end{abstract}

\begin{abstract}
An item of news brings statements and images that intertwine in the constitutive contradiction of subjects and senses. The news of a playful event held on the border that separates Mexico from the USA allows reading inputs to think about migratory processes, in the relationship between the symbolic borders constituted in and by language. This article provides analysis of excerpts from this news, focusing on different modes of formulation that move meanings in an update of memory from certain discursive positions. In the same way that the seesaws go up and down, in this symbolic movement of continuity and rupture, the words about migrants and refugees resonate affected by an imaginary construction about those who occupy these places.
\end{abstract}

Keywords: frontier; migrants; refugees; discourses

\section{PARA COMEÇAR}

Documentários, entrevistas, reportagens e até mesmo filmes de ficção mostram os desafios enfrentados por aqueles que, por diversas razões que violam seus direitos

\footnotetext{
${ }^{1}$ Uma versão introdutória deste artigo foi apresentada com o título No sobe e desce das gangorras: significar(se) refugiado, no VIII Encontro de Estudos da Linguagem e VII Encontro Internacional de Estudos da Linguagem - ENELIN, organizado pela Universidade do Vale do Sapucaí (UNIVAS), em 2019.

${ }^{2}$ Doutoranda em Linguística no Instituto de Estudos da Linguagem, da Universidade Estadual de Campinas - IEL/UNICAMP/CAPES.
} 
básicos como seres humanos, devem fazer a difícil escolha de deixar tudo pra trás e (re)começar em outro lugar. Não estamos falando dos migrantes econômicos, climáticos, mas sim daqueles que precisam buscar refúgio em outros lugares, inclusive para proteger suas vidas e as vidas de seus entes queridos. Eles são denominados refugiados desde o momento em que iniciam a jornada - antes mesmo de solicitar refúgio em outro país - e são mostrados a partir de construções imaginárias sobre o lugar de onde saíram, o percurso realizado durante o deslocamento, os lugares por onde passaram, entre outros fatores que contribuem para que os sentidos produzidos a partir deste imaginário sejam, na maioria dos casos, equívocos e derivem para outros sentidos.

A jornada de um refugiado é construída à base de incerteza, insegurança, medo, mas também vontade, coragem, determinação para não desistir no meio do caminho, ao mesmo tempo em que eles devem lidar com a constante expectativa do novo, do desconhecido, das inúmeras possibilidades, de tudo que não se pode antecipar, mas que irrompe em seu caminho e exige que ele se ajuste num curto espaço de tempo. Assim funcionam os processos migratórios, cuja discursividade se ancora basicamente num imaginário sobre os motivos que poderiam justificar o deslocamento, sobre a legitimidade daquele que fala da posição de refugiado, sobre sujeitos e sentidos que se constituem nesses processos discursivos.

A mídia contribui para a construção e manutenção desse imaginário ao fazer circular dizeres que reforçam sentidos estabilizados, significando o refugiado a partir da precariedade e da necessidade extrema, seja na voz de um locutor, num texto ou nas tantas imagens que são divulgadas sobre acontecimentos que movimentam sentidos sobre as migrações.

Este artigo foi pensado, a priori, com o propósito de analisar a notícia de um evento que diz respeito à questão das migrações, mas várias leituras dessa notícia, inclusive a partir de diferentes veículos midiáticos, permitem expandir o olhar e (re)direcionar as análises para desvendar outros sentidos possíveis. Mariani (1996) explica que o discurso jornalístico trabalha com a memória, seja trazendo algo novo, seja inserindo algo que se assemelha ao que já ocorreu anteriormente, "em uma ordem, ou seja, organizando filiações de sentidos possíveis para o acontecimento não apenas em termos de uma memória, mas também no que diz respeito aos desdobramentos futuros" (ibid., p. 63). Dessa forma, o texto jornalístico utiliza nomeações e explicações para tornar a notícia palatável. Segundo a autora, "esse processo de encadeamento cria a ilusão de uma relação significativa entre causas e consequências para os fatos ocorridos" (id.) e nesse funcionamento reside uma faceta do convencimento do discurso jornalístico, cujo objetivo é envolver os leitores.

Nos últimos anos, mais especificamente a partir de 2011, acompanhamos uma grande circulação de reportagens sobre conflitos em países do oriente médio, do continente africano e da América Latina, com imagens de destruição, barcos lotados, naufrágios, campos de detenção, também chamados campos de refugiados, filas intermináveis de pessoas que caminham rompendo fronteiras, entre outras imagens que significam na falta, naquilo que não se pode dizer. Carrenho (2019, p. 149) afirma que "estar diante do indizível é da ordem do deparar-se", e citando Mariani (2017), explica que estar diante daquilo que não se pode dizer "é da ordem do encontro com o Real", que não está inscrito na linguagem. Segundo a autora, isso não significa que não há 
nada, ou nada diferente a ser dito. Pelo contrário, as coisas difíceis de se colocar em palavras nos afetam, obrigando-nos a significá-las. Mas como pensar essa falta nos dizeres que circulam sobre aqueles que migram para refugiar-se de algo que não se pode dizer?

Deixar tudo para trás, sacrificar tudo, perder tudo, significa deparar-se com um real da ordem do indizível, do insuportável. As palavras não cabem e é neste momento que surgem as imagens para dizer de outra forma, fazer circular outros sentidos. Imagens que cristalizam momentos específicos, mas que também abrem janelas para gestos de interpretação, num movimento de remissão a outras imagens, a outros dizeres, em espaços e tempos distintos. Contudo, há imagens e textos que desestabilizam os sentidos, como as que são analisadas neste artigo.

\section{A CERCA}

Em outubro de 2020 - vésperas das eleições presidenciais dos Estados Unidos (doravante EUA), momento de campanha eleitoral -, "o atual presidente prometeu construir um muro com o México e acelerar as deportações dos mais de 10 milhões de estrangeiros sem documentos que vivem no país" (CORREIO, 2020). Esse é um momento pertinente para falar sobre a notícia que foi publicada em 2019 e fez circular imagens e textos que lançaram luz à questão das migrações a partir de um evento lúdico que, discursivamente, rompe com os sentidos estabilizados por dizeres estereotipados. Se por um lado circulam imagens que mostram barcos lotados, naufrágios, corpos em deslocamento pelo mar, corpos sem vida no mar, filas gigantescas de pessoas em suas caminhadas rumo ao desconhecido, campos com aspecto hostil, por outro lado há ações, manifestações, eventos que, no deslize, na deriva de sentidos, também significam o refugiado.

A fronteira entre os EUA e o México - ou seria a fronteira entre o México e os $\mathrm{EUA}^{3} \cdot$ ? -, é separada por uma cerca cuja construção foi autorizada por uma lei sancionada em 2006, pelo então presidente George W. Bush (BBC, 2006).

\footnotetext{
${ }^{3}$ Esta provocação parece pertinente na medida em que se observa maior incidência da formulação EUAMéxico nos títulos das reportagens que divulgam a notícia, mostrados adiante. Essa incidência poderia ser atribuída a alguns fatores, tais como: a ordem alfabética das letras iniciais $\mathbf{E}, \mathbf{M}$ ou a uma forma de dizer que se ancora num imaginário sobre a posição dos EUA, como um país que está sempre em disputa pela hegemonia mundial. Em ambos os casos, incide a ilusão de autonomia do sujeito que diz sobre algo/alguém (assujeitado pela ideologia) e a ilusão de transparência dos sentidos (estabilidade referencial) (cf. PÊCHEUX, 2014[1988]), que não leva em conta que mesmo numa formulação que apresenta maior regularidade os sentidos sempre podem ser outros.
} 




O título da reportagem da qual as imagens acima foram extraídas diz: "ao norte da fronteira, passado acalenta e futuro intimida" (FOLHA DE SÃO PAULO, 2017). Trata-se de uma edificação que não separa apenas dois países, mas famílias, sonhos, projetos de vida. O efeito simbólico desta cerca é tão devastador quanto sua própria existência que impõe limites, confina indivíduos, proíbe escolhas, materializando no concreto a não acolhida, a rejeição, a menos valia, o não direito de livre circulação, a não permissão para que possam buscar oportunidades e o escancaramento da desigualdade.

A representação física e simbólica dessa cerca foi, no entanto, colocada em jogo através da divulgação de um evento realizado num trecho da fronteira em 2019. A ação, registrada e publicada por alguns veículos midiáticos, coloca também em jogo os sentidos que circulam sobre migrantes que tentam atravessar a fronteira em busca de refúgio.

As análises desenvolvidas neste artigo, sobre enunciados e imagens apresentadas nas reportagens que noticiaram o evento, se ancoram nas noções teóricas elaboradas pelos estudiosos da Análise de Discurso (doravante AD) de base materialista, uma disciplina de entremeio que se fundamenta nos estudos de Michel Pêcheux (França) e nos trabalhos da professora Eni Orlandi e outros autores no Brasil. O dispositivo teórico-metodológico da $\mathrm{AD}$ é construído "num movimento pendular entre teoria e análise", explicado por Petri (2013, p. 40-41) como um movimento que recupera a historicidade daquilo "que vem de outro lugar para constituir sentidos na Análise de Discurso" e que é nesse "[...] ir e vir (da teoria para a análise e/ou vice-versa) que o pêndulo agita os processos de produção de sentidos sobre o corpus, movimentando a contemplação que estagnaria o analista e, consequentemente, o movimento de análise" (ibid., p. 42 - itálico da autora). 
Este trabalho também se fundamenta na obra de Susan Sontag, Diante da dor dos outros, e nos estudos realizados por Milene Leite (2016) que tratam dos efeitos de sentidos produzidos pelas imagens.

\section{O EVENTO, UM ACONTECIMENTO}

No texto O discurso: estrutura ou acontecimento, Michel Pêcheux (2008[1998]) se refere ao acontecimento como algo que se passa no "ponto de encontro de uma atualidade e uma memória" (ibid., p. 17). O autor trata o acontecimento não apenas como um fato novo, mas como algo que trabalha os efeitos desse fato no momento de sua ocorrência e na relação com a memória convocada, que é ao mesmo tempo trazida à tona e reorganizada.

Considerando a notícia em foco neste trabalho, podemos pensá-la como um acontecimento, levando em conta "a tensão entre descrição e interpretação no interior da análise do discurso" (ibid., p. 19), mas podemos pensá-la também como um acontecimento jornalístico, conforme Dela-Silva que o explica como:

[...] um fato, uma ocorrência no mundo; mas um fato que gera uma notícia, que por sua relevância perante a avaliação dos jornalistas do que se constitui como interesse público, merece estar presente nas edições diárias dos noticiários impressos ou eletrônicos. Trata-se de um acontecimento enquanto referente, com uma existência material no mundo; um acontecimento enquanto um fato que se inscreve na história do dia a dia, que o jornal e os jornalistas se propõem a escrever. (DELA-SILVA, 2008, p. 27)

A notícia que constitui o corpus deste artigo corresponde ao que a autora define como acontecimento jornalístico por mobilizar a questão das migrações, dos migrantes, do refúgio e dos refugiados, dos conflitos estabelecidos nas fronteiras, através de enunciados e imagens que produzem repercussões, analogias e remissões, no espaço da memória, entre outros efeitos. Ao circular em determinados veículos midiáticos, tais como Estado de Minas, Folha de São Paulo, G1, Metrópoles e TAB.UOL, exemplos mostrados ao longo deste trabalho, esse evento se converte em acontecimento jornalístico cuja ilusória transparência desvia o olhar do "confronto discursivo" (PÊCHEUX, 2008[1998], p. 20) que muito antes se materializa através de formulações que vão circulando e moldando o acontecimento, permitindo que ele seja manifestado como uma novidade ou silenciado. A "circulação-confronto de formulações" (ibid., p. 21), faz com que o acontecimento permita que refugiados sejam vistos, ditos, (res)significados de determinada(s) maneira(s) ou apagados, silenciados.

A notícia se refere ao evento que reuniu pessoas que pararam por alguns minutos dos dois lados de uma fronteira para brincar em gangorras cor-de-rosa e são os recortes dessa notícia que possibilitam questionar "o estatuto das discursividades que trabalham um acontecimento, entrecruzando proposições de aparência logicamente estável, suscetíveis de respostas unívocas (é sim ou não, é x ou y, etc.) e formulações irremediavelmente equívocas" (ibid., p. 28).

Seguindo neste percurso, observemos as formulações dos títulos publicados nos veículos midiáticos: 
1. 1. "As ações de um lado têm consequências no outro", diz criador de gangorra entre México e EUA". (ESTADO DE MINAS, 2019)

2. 2. Confira legenda vencedora para foto de gangorra na fronteira entre EUA e México. (FOLHA DE SÃO PAULO, 2019)

3. 3. Arquiteto instala gangorras na cerca entre EUA e México. (G1, 2019a)

4. 4. 'Muito comovente', diz arquiteto que montou gangorra na fronteira entre México e EUA. (G1, 2019b)

5. 5. Arquiteto instala gangorras na fronteira EUA-México para unir pessoas. (METRÓPOLES, 2019)

6. 6. Na fronteira entre EUA e México, gangorras unem crianças dos dois países. (TAB.UOL, 2019)

Como destacado anteriormente em nota, o jornal Estado de Minas e o G1, em uma de suas reportagens, formulam México e EUA ao divulgar a notícia. Esta primeira provocação é pertinente na medida em que, discursivamente, esse gesto significa e nos diz sobre um possível posicionamento do sujeito que coloca os dizeres em circulação. Os títulos acima trazem a formulação EUA-México em quatro dos seis jornais indicados como exemplos. Isso ocorre com as publicações feitas pelo G1(2019a), Folha de São Paulo (2019), Metrópoles (2019) e TAB.UOL (2019). Considerando apenas os títulos publicados por estes veículos midiáticos e não o conteúdo das reportagens referentes a estes títulos, observamos que o G1 é o único que se vale das duas formulações: EUAMéxico (ibid., 2019a) e México-EUA (ibid., 2019b).

Essa provocação nos permite pensar no interdiscurso que opera nessas formulações. Carrenho (2019, p. 67), fazendo referência ao objeto "aborto", diz sobre um objeto que é dado, "que não necessita de elaboração no fio do discurso (intradiscurso)", remetendo ao que Pêcheux (2014[1988]) explica como efeito de préconstruído, referente às formulações que recortadas de determinadas posições discursivas são elaboradas a partir do interdiscurso, daquilo que já foi pensado "antes, em outro lugar independentemente" (ibid., p. 149) e que aparece como evidência no intradiscurso.

Todo mundo sabe ${ }^{4}$ que a construção da cerca foi aprovada pelos EUA; que este país é mostrado e dito pela constante disputa pela hegemonia mundial; que há um fluxo maior de migrantes mexicanos e de outros países das Américas em direção aos EUA e não o movimento contrário. Esses dizeres produzem sentidos numa naturalização que faz com que o sujeito interpelado coloque os EUA em primeiro plano na ordem da formulação.

A partir destas reflexões e compreendendo que a notícia em questão oferece algumas entradas de leitura, este é o momento de falar sobre as condições de produção para que possamos seguir neste percurso analítico com maior profundidade.

Segundo os jornais G1 e Estado de Minas, a montagem de três gangorras na fronteira entre México e EUA ocorreu no período entre o final de julho e o início de agosto de 2019. De acordo com esses jornais e outros veículos midiáticos que

\footnotetext{
${ }^{4} \mathrm{O}$ todo mundo sabe naturalizado pela interpelação ideológica que dissimula os sentidos tornando-os transparentes.
} 
publicaram a notícia, a divulgação deste evento deu visibilidade à questão das migrações ao mostrar o impacto de uma ação lúdica que resultou numa brincadeira envolvendo participantes - adultos e crianças - dos dois países.

Desenhadas por dois professores de universidades da Califórnia que, segundo as reportagens, passaram 10 anos idealizando o projeto, as três gangorras cor-de-rosa foram instaladas de forma a atravessar trechos da "cerca de ferro" (G1, 2019a) - ou "parede de aço" (TAB.UOL, 2019) - que divide esses países. A foto (abaixo) publicada pela Folha de São Paulo (2019) mostra o que a legenda não diz, isto é, que a brincadeira não ficou restrita às crianças. Os adultos também foram contagiados pela proposta $\mathrm{e}$ pegos pela tentação de experimentar algo inusitado num cenário que se significa e é significado pela separação, pela divisão.

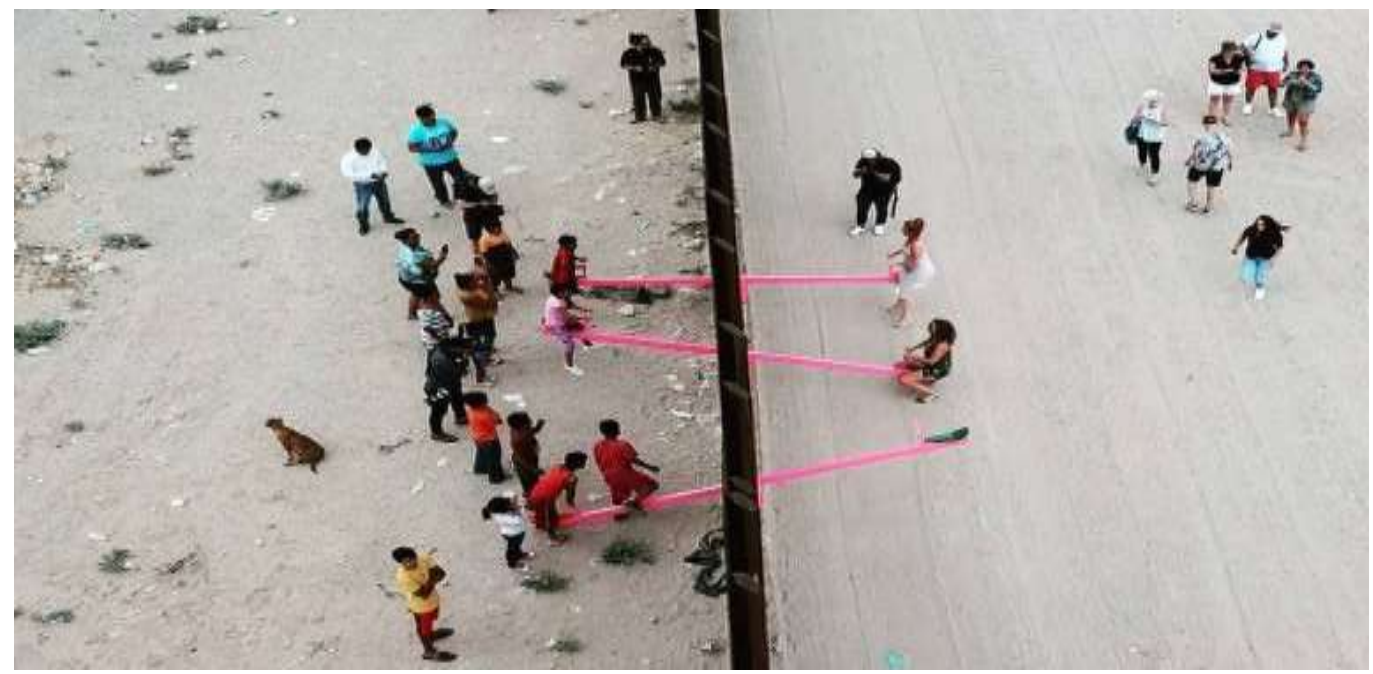

Crianças do México e dos EUA brincam com gangorra instalada no muro da fronteira - Rael San Fratello / Reuters. Disponível em: https://www1.folha.uol.com.br/paineldoleitor/2019/08/confira-legendavencedora-para-foto-de-gangorra-na-fronteira-entre-eua-e-mexico.shtml. Acesso em: 29/09/2019.

A dureza do ferro ganha novos sentidos quando a cerca é atravessada pelas gangorras que, ao ocuparem os dois lados da fronteira, transpõem limites e se significam num irresistível convite. Experimentar, brincar, romper e resistir às formações discursivas dominantes que estabilizam sentidos para conectar-se com o outro, (re)encontrar o outro. Aquilo que deveria e poderia ser dito já não tem o mesmo funcionamento. No lugar, o inesperado, a surpresa, a diversão, a possibilidade de cooperação dos dois lados para fazer acontecer a aventura proposta pela instalação dos brinquedos.

\section{EFEITOS DE SENTIDOS NO QUE É DITO E MOSTRADO SOBRE OS SOLDADOS DA FRONTEIRA}

Nas reportagens, lemos que o evento durou apenas 40 minutos, mas gerou vídeos e fotos que repercutiram nas redes sociais. Lemos também que a atividade não foi impedida pelos soldados que monitoravam a fronteira. "A equipe não chegou a pedir nenhum tipo de autorização para montar o brinquedo, mas nenhum soldado - mexicano 
ou americano - tentou impedi-los, relatou o arquiteto. Alguns até sorriram." (G1, 2019b - grifos do autor).

Considerando o funcionamento dos processos discursivos entre sujeitos interpelados pela ideologia e pelo inconsciente, os gestos analíticos ${ }^{5}$ são direcionados ao enunciado que se refere aos soldados mencionados na reportagem: "Alguns até sorriram". Ao utilizar o advérbio de inclusão, a formulação produz efeitos de sentidos a partir de um imaginário sobre a conduta de um soldado, aquele que, como todo mundo sabe, se encontra em constante vigilância, fiscalizando, monitorando, impedindo o acesso ao outro lado da fronteira. Dito dessa maneira, "até sorriram", o que se produz é um efeito de não identificação com a antecipação produzida pela imagem dos soldados que guardam a fronteira do México com os EUA, com suas fardas camufladas, coturnos pesados, coletes à prova de bala, capacetes, munição pendurada na cintura para abastecer suas armas potentes, letais, com sua mirada direta, em constante estado de alerta... como se estivessem sempre a postos para uma batalha iminente. Essa descrição traz à tona a evidência dos sentidos, aquilo que é dito enquanto fato: não se espera sorrisos de soldados que ocupam a posição de guardiões dessa fronteira. Descrito desta forma, podemos pensar nas seguintes construções parafrásticas, aludindo ao velho clichê homem não chora: soldado não chora, soldado não sorri, soldado não se emociona, soldado não se sensibiliza.

\section{Contudo, segundo Pêcheux (2008[1998]):}

[...] toda descrição está intrinsicamente exposta ao equívoco da língua: todo enunciado é intrinsicamente suscetível de tornar-se outro, diferente de si mesmo, se deslocar discursivamente de seu sentido para derivar um outro. Todo enunciado, toda sequência de enunciados é, pois, linguisticamente descritível como uma série [...] de pontos de deriva possíveis, oferecendo lugar a interpretação. (ibid., p. 53).

A elaboração proposta por Pêcheux reforça a força simbólica de um dizer que se ancora numa construção imaginária do universo machista, homem não chora, para referir a um imaginário sobre soldados, guardas, militares em ação, significados como máquinas de combate, prontas para atacar e defender os propósitos daqueles que as acionam em condições específicas, tais como as condições mostradas na foto a seguir: a guarda da fronteira entre México e EUA.

\footnotetext{
${ }^{5}$ Lembrando que esse gesto aponta para o sujeito que é dito a partir da posição discursiva de um soldado alocado na fronteira entre México e EUA.
} 


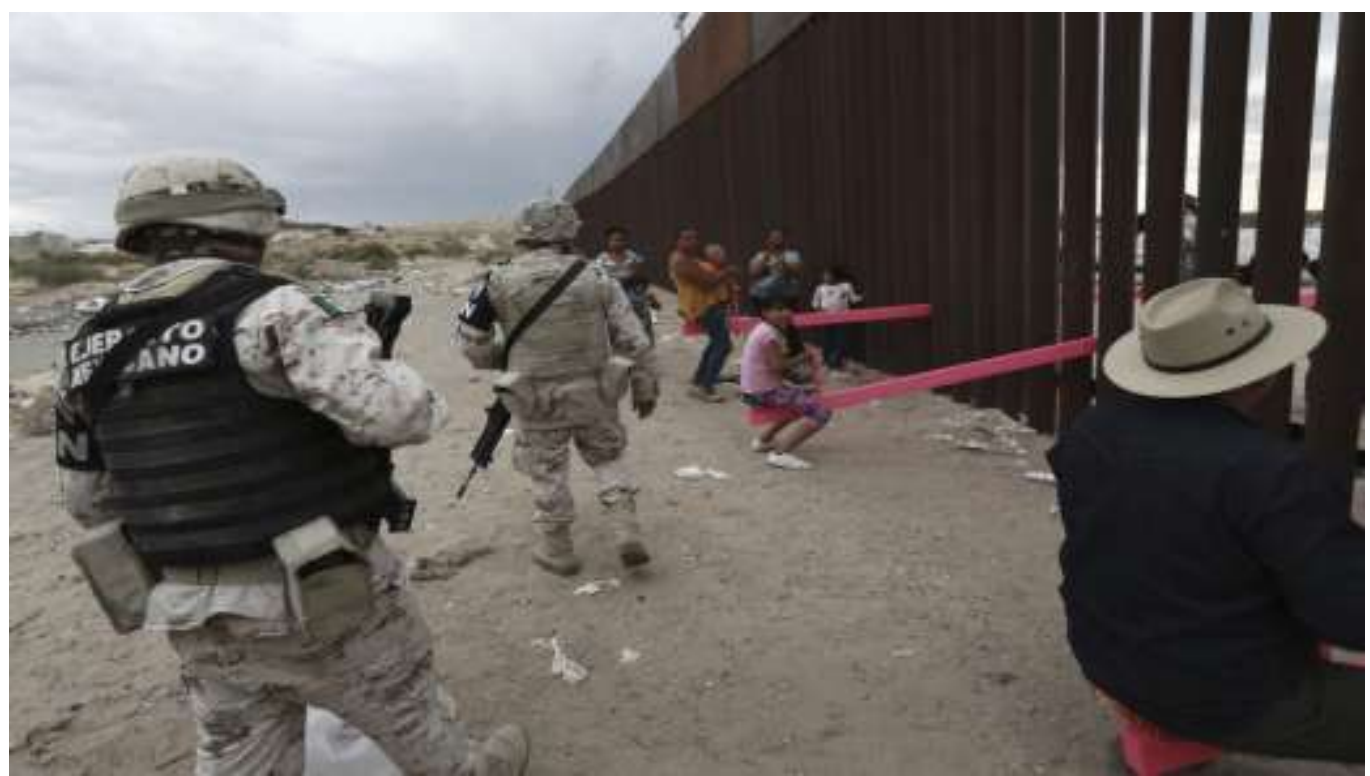

Os soldados - de ambos os lados - não tentaram impedir a montagem da gangorra, contou o arquiteto Ronald Rael. - Foto: Christian Chavez/AP. Disponível em: https://g1.globo.com/mundo/noticia/2019/07/31/muitocomovente-diz-arquiteto-que-montou-gangorra-na-fronteira-entre-mexico-eeua.ghtml Acesso em: 12/08/2019b

Entretanto, na legenda da foto acima, lemos que os soldados não reagem como seria esperado, naturalizado, a este acontecimento que desestabiliza os efeitos simbólicos que o enunciado e a imagem colocam em jogo. Tanto os sentidos sobre a parede de aço quanto os sentidos que são produzidos a partir do que é dito sobre soldados designados a resguardar essa edificação derivam.

Nessas condições de produção, sujeitos e sentidos, que se constituem ao mesmo tempo, são (res)significados pela não identificação com a formação discursiva dominante. De sujeitos que deveriam impedir que as gangorras fossem instaladas ou que as pessoas se aproximassem delas, defendendo os interesses do Estado e representando simbolicamente a continuidade da própria cerca que promove a manutenção das diferenças, esses soldados são ditos por um ato que rompe com essa regulação fazendo com que os sentidos sejam deslocados. O enunciado "Alguns até sorriram", destacado em negrito pelo próprio veículo midiático que o publicou, diz sobre um "jogo de força na memória, sob o choque do acontecimento", explicado por Pêcheux $(2015$, p. 47) como:

- um jogo de força que visa manter uma regulação pré-existente com os implícitos que ela veicula, conformá-la como "boa forma", estabilização parafrástica negociando a integração do acontecimento, até absorvê-lo e eventualmente dissolvê-lo;

- mas, também, ao contrário, o jogo de força de uma "desregulação" que vem perturbar a rede dos "implícitos" (id.).

Este mesmo enunciado também remete a uma memória discursiva sobre as ações realizadas por soldados que se encontram alocados em fronteiras por onde passam os migrantes. $\mathrm{Na}$ equivocidade, o sujeito que enuncia "alguns até sorriram" diz sobre o momento em que, em sua jornada rumo ao outro lugar, os migrantes se deparam com o desafio de atravessar a fronteira. Uma ação arriscada que aumenta a incerteza e o medo. 
Medo de serem pegos, encarcerados para posteriormente serem obrigados a retornar ao país de onde se viram forçados a fugir, muitas vezes para preservar a própria vida. A fronteira escancara o risco, o desespero, a impossibilidade; a cerca materializa e consolida a rejeição, a não acolhida. Um espaço cercado que (re)afirma que migrantes, sendo ou não refugiados, não são bem-vindos.

Tanto o enunciado "alguns até sorriram" como a imagem dos soldados próximos à cerca no momento em que a atividade lúdica foi colocada em prática, produzem efeitos sobre um acontecimento no qual os sentidos se constituem numa contraidentificação com as formações discursivas dominantes que dizem sobre a fronteira, a cerca, os soldados. Da mesma forma, a imagem das gangorras cor-de-rosa rompendo aquele trecho da parede escura cercada por soldados que não se opõem à ação, produz outros sentidos para este cenário árido e hostil. Didi-Huberman diz que:

Nesse mundo onde o inimigo não para de vencer e onde o horizonte parece ofuscado pelo reino e por sua glória, o primeiro operador político de protesto, de crise, de crítica ou de emancipação deve ser chamado imagem, no que diz respeito a algo que revela, capaz de transpor o horizonte das construções totalitárias. (DIDIHUBERMAN, 2011[2009], p. 118 - grifos do autor).

Os efeitos da imagem descrita acima, considerando as palavras de DidiHuberman, funcionam como feixes de luz no cenário das migrações.

\section{O COR-DE-ROSA DAS GANGORRAS}

Nas reportagens, lemos que a instalação das gangorras teve como propósito problematizar, de forma lúdica, o papel da fronteira na manutenção da desigualdade e do desequilíbrio laboral e social. Instaladas no meio da cerca alta, constantemente monitorada de ambos os lados, as gangorras sobem e descem movimentando sentidos sobre esse ir e vir proibido. Nesse movimento, que por alguns minutos rompe a barreira entre os países, sujeitos e sentidos são também constituídos por um já-dito sobre ser diferente, o diferente que deve ser contido, limitado, impedido de circular.

O espaço específico da fronteira onde estão instaladas as gangorras é ressignificado no subir e descer dos brinquedos que atravessam a cerca. Durante 40 minutos de brincadeira, o espaço funciona como se a cerca não fosse um impedimento e aquela grande estrutura de ferro, que naquele momento sustenta os brinquedos, passa a aproximar e não mais separar as pessoas que circulam dos dois lados. As gangorras corde-rosa, sustentadas pela própria edificação escura e pesada que define a barreira entre os dois países, o limite e a impossibilidade de seguir adiante, produzem uma ruptura de sentidos que também ressignifica o entorno árido. Elas convidam, chamam para uma brincadeira que só é possível acontecer pela interdependência entre dois participantes, já que é necessário que aquele que se senta de um lado dê o impulso que produzirá efeitos no parceiro que se encontra sentado do outro lado. Enquanto um sobe o outro desce, ao mesmo tempo, marcando um ritmo acordado implicitamente. Pelo movimento e pelo ritmo das gangorras, os sentidos cruzam as fronteiras e se dispersam.

Há vários recortes, várias entradas de leituras possíveis para os enunciados e as imagens que compõem as reportagens referentes à notícia do evento das gangorras cor- 
de-rosa. Na transparência, as gangorras dão visibilidade à desigualdade, ao desequilíbrio, mas numa leitura para além da evidência dos sentidos é possível compreender que as significações se dão num "discurso que se constrói na base de uma relação polêmica e de antítese em relação com o outro" (INDURSKY, 2013, p. 265 grifo da autora). A estrutura de ferro, a parede de aço, conforme descrita pelo TAB.UOL, funciona como um “já-lá” (PETRI, 2013, p. 46), um objeto que já diz sobre os indivíduos que não podem ultrapassar um limite específico, num espaço determinado e num tempo em que os discursos sobre as migrações atualizam memórias que os tornam cada vez menos acolhedores. $\mathrm{O}$ tom rosa que dá cor às gangorras, no entanto, funciona num movimento de resistência, pelo contraste com a aridez do entorno. "As áreas de fronteira são áreas de contrastes - e o rosa faz contraste com o lixo, o deserto, o metal" G1 Mundo (2019b).

Mas por que cor-de-rosa? Por que não outra cor vibrante tal como o amarelo, por exemplo, que poderia produzir efeitos semelhantes, se olhássemos apenas para a evidência dos sentidos e pensássemos na forma como essa cor contrastaria com as cores que preenchem esse espaço?

Citando o arquiteto, a reportagem do G1 (id.) explica a escolha do rosa como uma forma de lembrar "a época de violência em Ciudad Juárez, principalmente nos anos 90, em que várias mulheres foram mortas ou despareceram" (id.). Entretanto, na discursividade, ao atravessar a cerca escura que impõe limites, essa cor diz muito mais. $\mathrm{O}$ cor-de-rosa diz sobre as mulheres migrantes, as mulheres refugiadas que sobreviveram às perdas e às violações; que se viram obrigadas a tomar decisões difíceis, penosas; as mulheres que não são vistas, tampouco escutadas, e que por isso mesmo devem lutar ainda mais pelo direito a uma vida digna; as mulheres que migram sozinhas após se verem obrigadas a abandonar seus lares e suas famílias para proteger-se (e proteger seus familiares); também aquelas que carregam os filhos nos braços, na barriga; as que retornam para buscar seus filhos, suas mães; e as que perderam seus filhos, maridos, pais, casas. Mulheres mutiladas física e emocionalmente, que não têm tempo para sentir suas dores, viver seus lutos e se veem obrigadas a deslocar-se para buscar refúgio, carregando a vida numa mochila e uma alma pesada de recordações. Mulheres que carregam a dor gerada pelas inúmeras formas de violência e pelo abandono, mas que, apesar disso tudo, também conseguem libertar a criança que nelas habita e sorrir ao sentar no brinquedo cor-de-rosa, como ilustra a foto a seguir, que não traz legenda descritiva, mas que diz tanto. 


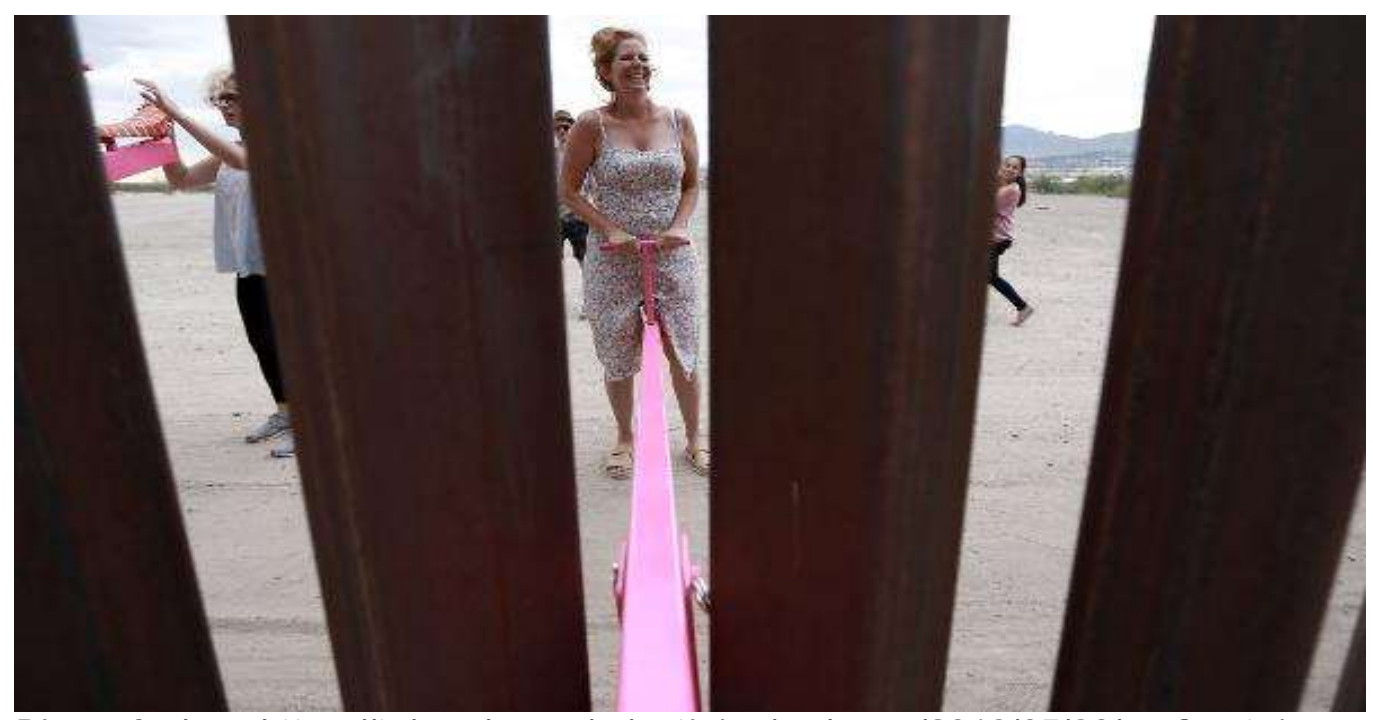

Disponivel em https://tab.uol.com.br/noticias/redacao/2019/07/30/na-fronteiraentre-eua-e-mexico-gangorras-unem-criancas-dos-dois-paises.htm. Acesso em: 12/08/2019.

Sontag (2003) explica que as fotos são "meios de tornar 'real' (ou 'mais real') assuntos que as pessoas socialmente privilegiadas, ou simplesmente em segurança, talvez preferissem ignorar [...]. Olhem, dizem as fotos, é assim" (p. s/n - grifos da autora). É assim que essa mulher anônima, que pode ou não ser uma mulher refugiada, cuja imagem a captura sentada numa gangorra cor-de-rosa em meio aos espaços espremidos da cerca de ferro, sorri como criança... apesar de tudo. Sontag afirma também que "numa era sobrecarregada de informação, a fotografia oferece um modo rápido de apreender algo e uma forma compacta de memorizá-lo. A foto é como uma citação ou uma máxima ou provérbio" (id.).

Sobre os sentidos produzidos por imagens divulgadas pelos veículos midiáticos no ambiente virtual, Leite (2016, p. 53) explica que "o discurso imagético [...], nos jornais online, não se constrói fora da lógica do mercado". A autora argumenta que, por um lado, os "jornais são empresas, vendem produtos". Contudo, outro direcionamento se dá no momento em que, "enquanto gesto de inscrição do sujeito numa região de sentidos", a análise das fotografias, pelo viés discursivo, pode funcionar ao mesmo tempo como testemunho, "pelo caráter do que têm a transmitir".

Seguindo as reflexões propostas por Leite, ao olharmos para as imagens divulgadas nas reportagens como testemunho de uma ação lúdica, cujos sentidos se dispersam ao convocar memórias de uma discursividade sobre os processos migratórios e sobre os sujeitos que são constituídos a partir dos dizeres que categorizam esses processos - dizeres sobre migrações econômicas, migrações ambientais ou climáticas, migrações por conta de guerras e violações de direitos humanos -, devemos considerar também o gesto de interpretação de um sujeito que, ao registrar as fotografias sob determinados ângulos e não outros, se posiciona identificando-se com determinada formação discursiva.

No gesto de produzir uma imagem, o sujeito diz a partir de sua inscrição subjetiva, que tanto é a de divisão pelo inconsciente quanto a da interpelação ideológica. $E$ isso é inscrição na linguagem, no simbólico. É por isso que o sujeito diz como pode; não 
diz tudo. No "eu vi" da fotografia, no "eu estava lá" e a prova é "isto" (a imagem), uma posição do sujeito se marca e se inscreve em uma formação discursiva para (poder e dever) dizer. (LEITE, 2016, p. 53 aspas e negritos da autora).

As fotos publicadas nas reportagens testemunham um evento, uma brincadeira entre adultos e crianças em gangorras cor-de-rosa instaladas nos espaços abertos de uma cerca que impede que esses mesmos adultos e essas mesmas crianças possam prosseguir em sua jornada. Dessa forma, as fotos também testemunham aspectos da dura realidade daqueles que precisam migrar. Contudo, é justamente no atravessamento desses espaços abertos, no subir e descer das gangorras, que opera a resistência e o caráter simbólico que constitui a cerca é colocado em jogo, colocando em jogo também a determinação do Estado que impõe restrições e ameaça aqueles que precisam se deslocar.

A reportagem do G1 registra a ironia produzida a partir do acontecimento das gangorras cor-de-rosa, ao dizer que:

[...] o muro virou literalmente o ponto de sustentação para as relações dos EUA com o México e crianças e adultos foram conectados de forma significante em ambos os lados com o reconhecimento de que as ações que acontecem em um lugar devem ter consequências diretas do outro. $(\mathrm{G} 1,2019 \mathrm{a})$

A ideia das gangorras passa a ser "a ideia da brincadeira falando de ações políticas" (G1, 2019b). Os dizeres sobre esse evento produzem efeitos de sentidos a partir de um imaginário sobre o outro que teve a necessidade de se deslocar, de migrar, subjetivando-o muito além daquele que incomoda, daquele que é dito como uma ameaça na disputa por espaços e oportunidades. Assim como as gangorras precisam de dois lados trabalhando conjuntamente para que a brincadeira aconteça, é preciso repensar esse imaginário, reformular os dizeres que circulam produzindo fronteiras simbólicas para que se possa produzir e movimentar outros sentidos sobre aqueles que ocupam a posição de migrantes e de refugiados.

\section{PARA FINALIZAR}

Esse gesto analítico foi iniciado com uma provocação sobre os efeitos de sentidos produzidos pela formulação EUA-México/México-EUA e ao longo deste percurso encontramos outras possibilidades de leitura para a notícia sobre a montagem das gangorras cor-de-rosa que foram instaladas na cerca que divide a fronteira entre os dois países.

Nosso olhar foi direcionado a dois sujeitos antagônicos que produzem efeitos de sentidos sobre este acontecimento: (1) o soldado que guarda a fronteira - representando a força bruta, o poder do Estado, funcionando como agente repressor; e (2) a mulher, que não apenas representa a fragilidade daqueles que se veem compelidos a se deslocar, mas também se converte em fonte de inspiração para a escolha da cor rosa das gangorras. Sujeitos e sentidos se constituem nos enunciados e nas imagens sobre o evento, produzindo efeitos também no conjunto de dizeres que significam os processos migratórios, a busca por refúgio, a condição dos migrantes e dos refugiados. 
Enquanto sujeitos interperlados pela ideologia, a discursividade que os significa funciona a partir de uma ilusão de onipotência dos sentidos, de uma única significação possível para o que é dito sobre eles (ORLANDI, 2008[1988]). De acordo com essa única possibilidade naturalizada pela ideologia, funcionando na evidência, de um lado há o soldado que ocupa essa posição que o significa basicamente como um cumpridor de ordens que não deve se abalar, se sensibilizar, empatizar. A partir dessa posição discursiva, esse sujeito é significado pela identificação com a formação discursiva dominante que determina aquilo que pode e deve ser dito sobre ser soldado e sobre ser esse soldado alocado nessa fronteira, destinado a salvaguardar os limites estabelecidos pelo Estado. Do outro lado, assim como há o soldado que é significado por sua brutalidade, disciplina e obediência no cumprimento da missão que lhe é designada, há a mulher dita prioritariamente pela fragilidade que convoca uma memória discursiva que remete aos vários abusos sofridos por mulheres, não apenas migrantes e/ou refugiadas. Uma memória que reforça os efeitos da desigualdade que, levada ao extremo, permite a naturalização do desrespeito, possibilitando que atos de extrema crueldade sejam deflagrados contra mulheres.

O enunciado do G1 que diz que um dos motivos para a escolha da cor rosa foi o de lembrar "a época de violência em Ciudad Juárez, principalmente nos anos 90, em que várias mulheres foram mortas ou despareceram" (ibid., 2019b), remete às memórias que são convocadas e atualizadas nesse dizer: das mulheres que são torturadas ou forçadas a ver seus maridos, filhos e outros familiares serem torturados; daquelas que são usadas como armas de guerra; das que são obrigadas a viver em seus corpos violados, mutilados, entre tantas outras atrocidades que deixam cicatrizes profundas, destroçam sua autoestima e lhes roubam o direito de sonhar com uma vida digna.

[...] é na formulação que a linguagem ganha vida, que a memória se atualiza, que os sentidos se decidem, que o sujeito se mostra (e se esconde). [...] Na formulação, - pelo equívoco, falha da língua inscrita na história - corpo e sentido se atravessam. Formular é dar corpo aos sentidos" (ibid., p. 9).

Pelas análises da formulação da reportagem do G1 (2019b) que diz sobre a forma como as gangorras foram montadas e sobre o comportamento dos soldados, nos deparamos com o real da língua, naquilo que escapa: "A equipe não chegou a pedir nenhum tipo de autorização para montar o brinquedo, mas nenhum soldado - mexicano ou americano - tentou impedi-los, relatou o arquiteto. Alguns até sorriram.” (id. - grifos do autor). O real que neste recorte também se materializa no uso dos pronomes indefinidos nenhum e alguns, coloca em jogo os sentidos de evidência, não permitindo distinguir os soldados americanos dos soldados mexicanos e fazendo com que os sentidos que são produzidos a partir dos enunciados e das imagens da fronteira que separa os EUA do México deslizem. Essa é a "noção de Real mais próxima da do campo psicanalítico, como aquilo que é da ordem do inominável, do impossível de simbolizar e atribuir sentido" (CARRENHO', 2019, p. 35).

\footnotetext{
${ }^{6}$ Carrenho, em nota de rodapé, se refere à apropriação que Pêcheux faz da noção de Real, aproximando-a ora do campo psicanalítico e ora de um Real da ordem do que se pode delimitar, especificar e até mesmo nomear, isto é, no momento em que diz que o Real da língua é o equívoco.
} 

deslizam:

Contudo, relembrando o que diz Orlandi (2012), na formulação os sentidos

Tomando esta noção de Real para pensar os efeitos de sentidos produzidos pela imagem das mulheres que aparecem na foto a seguir, por exemplo - considerando, como já foi dito anteriormente, a forma como as mulheres migrantes e refugiadas são significadas pelas várias faces da dor -, vemos uma imagem paradoxal que convoca outras memórias, permitindo-nos construir as seguintes paráfrases:

(1) o brinquedo cor-de-rosa que diz sobre a mulher limitada de um lado da cerca;

(2) a mulher na gangorra cor-de-rosa, impedida de ultrapassar a parede de ferro;

(3) no brinquedo cor-de-rosa, a mulher só pode olhar através das frestas da cerca.

E também:

(4) a mulher que brinca nas gangorras cor-de-rosa e liberta sua criança interior;

(5) a mulher que interage em igualdade com o outro que está do outro lado; lado.

(6) a mulher que se sente acolhida no brinquedo que a conecta com o outro



Disponível em https://www.metropoles.com/mundo/arquiteto-instala-gangorrasna-fronteira-eua-mexico-para-unir-pessoas. Acesso em: 12/08/2019.

As paráfrases, assim como a imagem, permitem que os sentidos se desloquem entre a fragilidade da mulher que busca refúgio em outro lugar e a força da mulher que toma a decisão de se lançar no mundo, nessa jornada em busca de melhores oportunidades, a coragem da mulher que diz não à violência, a determinação da mulher que luta por seus direitos.

O soldado, a mulher, as crianças, migrantes, refugiadas, produzem sentidos que se materializam no subir e descer das gangorras que atravessam a cerca da fronteira. Sujeitos que dizem sobre os processos migratórios e sobre o refúgio, que significam e 
são significados a partir do subir e descer dos barcos, do movimento das ondas do mar Mediterrâneo, das lembranças das vidas sugadas pelas ondas, num ir e vir de um lugar ao outro, deixando uma vida para trás para buscar outra possibilidade de vida ou para perder-se na trilha de um deserto que abriga corpos inertes e ossos que compõem as marcas que produzem sentidos sobre aqueles que se encontram na condição de migrante e refugiado.

\section{REFERÊNCIAS}

BBC BRASIL. Bush assina lei que prevê muro na fronteira com México. Arizona. Publicado em: 26/10/2006. Disponível em: https://www.bbc.com/portuguese/reporterbbc/story/2006/10/061026_bush_muro_crg. Acesso em: 22/09/2019.

CARRENHO, J. M. Eu vou contar e outras cenas de testemunhos de mulheres: um estudo discursivo das relações entre arquivo, trauma e língua. Monografia. Bacharelado em Linguística, Instituto de Estudos da Linguagem, Universidade Estadual de Campinas, Campinas, SP: [s.n.], 2019.

CORREIO. A um mês das eleições nos EUA, dois documentários abordam deportação de imigrantes. Internacional. Publicado em: 05/10/2020. Disponível em: https://correio.rac.com.br/_conteudo/2020/10/agencias/1012257-a-um-mes-daseleicoes-nos-eua-dois-documentarios-abordam-deportacao-de-imigrantes.html. Acesso em: 27/10/2020.

DELA-SILVA, S. C. O acontecimento discursivo da televisão no Brasil: a imprensa na constituição da TV como grande mídia. Tese. Doutorado em Linguística, Instituto de Estudos da Linguagem, Universidade Estadual de Campinas, Campinas, SP: [s.n.], 2008.

DIDI-HUBERMAN, G. Sobrevivência dos vaga-lumes. Belo Horizonte: Ed. UFMG, 2011[2009].

ESTADO DE MINAS. "As ações de um lado têm consequências no outro", diz criador de gangorra entre México e EUA. Internacional. Publicado em: 07/08/2019. Disponível em:

https://www.em.com.br/app/noticia/internacional/2019/08/07/interna_internacional,107 5509/criador-gangorra-mexico-eua-entrevista.shtml. Acesso em: 12/08/2019.

FOLHA DE SÃO PAULO. Ao norte da fronteira, passado acalenta e futuro intimida. Publicado em: 26/06/2017. Disponível em: https://arte.folha.uol.com.br/mundo/2017/um-mundo-de-muros/eua/na-terra-de-trump/. Acesso em: 12/08/2019. Confira a legenda vencedora para foto de gangorra na fronteira entre EUA e México. Publicado em : 15/08/2019. Disponível em : https://www1.folha.uol.com.br/paineldoleitor/2019/08/confira-legenda-vencedora-parafoto-de-gangorra-na-fronteira-entre-eua-e-mexico.shtml. Acesso em: 29/09/2019. G1. Arquiteto instala gangorras na cerca entre EUA e México. Mundo. Publicado em: 30/07/2019. Disponível em: https://g1.globo.com/mundo/noticia/2019/07/30/arquitetoinstala-gangorras-na-cerca-entre-eua-e-mexico.ghtml. Acesso em: 12/08/2019a.

"Muito comovente", diz arquiteto que montou gangorra na fronteira entre México e EUA. Mundo. Publicado em: 31/07/2019. Disponível em:

https:agazzi//g1.globo.com/mundo/noticia/2019/07/31/muito-comovente-diz-arquitetoque-montou-gangorra-na-fronteira-entre-mexico-e-eua.ghtml. Acesso em: 12/08/2019b. 
INDURSKY. F. A fala dos quartéis e as outras vozes. $2^{\mathrm{a}}$ ed. Campinas, SP: Editora da Unicamp, 2013.

LEITE, M. M. C. Uma infância em imagen(s) - uma análise do funcionamento de fotografias no discurso jornalístico. Dissertação. Mestrado em Estudos da Linguagem, Programa de Pós-Graduação em Estudos da Linguagem, Universidade Federal Fluminense, Niterói, RJ: [s.n.], 2016.

MARIANI, B. O comunismo imaginário: práticas discursivas da imprensa sobre o PCB (1922-1989). Tese. Doutorado em Linguística, Instituto de Estudos da Linguagem, Universidade Estadual de Campinas, Campinas, SP: [s.n.], 1996.

METRÓPOLES. Arquiteto instala gangorras na fronteira EUA-México para unir pessoas. Publicado em: 30/07/2019. Disponível em: https://www.metropoles.com/mundo/arquiteto-instala-gangorras-na-fronteira-euamexico-para-unir-pessoas. Acesso em: 12/08/2019.

ORLANDI, E. P. Discurso e leitura. $8^{a}$ ed. São Paulo: Cortez; Campinas, SP: Editora da Universidade Estadual de Campinas, 2008[1988].

Discurso e Texto: formulação e circulação dos sentidos. $4^{\mathrm{a}}$ ed. Campinas, SP: Pontes Editores, 2012.

PÊCHEUX, M. O discurso: estrutura ou acontecimento. Trad. Eni P. Orlandi $-5^{\text {a }}$ edição. Campinas, SP. Pontes Editores: 2008[1998].

Semântica e Discurso: uma crítica à afirmação do óbvio. Tradução Eni Puccinelli Orlandi et al. $5^{\text {a }}$ ed. Campinas, SP: Editora da Unicamp, 2014[1988].

Papel da Memória. In: ACHARD, P. [et al]. Papel da Memória. Trad. José H. Nunes $-4^{\mathrm{a}}$ ed. - Campinas, SP: Pontes Editores, 2015.

PETRI, V. O funcionamento do movimento pendular próprio às análises discursivas na construção do "dispositivo experimental" da Análise de Discurso. In: PETRI, V. e DIAS, C. (org.). Análise do discurso em perspectiva: teoría, método e análise. Santa Maria: Ed. da UFSM, 2013. pp. 39-48.

SONTAG, S. Diante da dor dos outros. Rio de Janeiro: Companhia das Letras, versão digital Kobo, 2003.

TAG.UOL. Na fronteira entre EUA e México, gangorras unem crianças dos dois países. Notícias. Publicado em: 30/07/2019. Disponível em: https://tab.uol.com.br/noticias/redacao/2019/07/30/na-fronteira-entre-eua-e-mexicogangorras-unem-criancas-dos-dois-paises.htm. Acesso em: 12/08/2019.

Artigo recebido em: out. de 2020.

Aprovado e revisado em: jan. de 2021.

Publicado em: fev. de 2021.

Para citar este texto:

RIZENTAL, Sabrina Sant'Anna. No sobe e desce das gangorras: Sentidos que rompem fronteiras. Entremeios [Revista de Estudos do Discurso, ISSN 2179-3514, on-line, www.entremeios.inf.br], Seção Estudos, Programa de Pós-Graduação em Ciências da Linguagem (PPGCL), Universidade do Vale do Sapucaí (UNIVÁS), Pouso Alegre (MG), vol. 23, p. 59-75, Edição especial/ 2020.

DOI: http://dx.doi.org/10.20337/ISSN2179-3514revistaENTREMEIOSvol23pagina59a75 